\title{
Erratum
}

\section{A Novel, Practical Synthesis of Sulfonyl Chlorides from Thiol and Disulfide Derivatives}

Kiumars Bahrami,* Mohammad Mehdi Khodaei,* Mehdi Soheilizad Synlett 2009, 2773.

Heterocyclic sulfonyl chlorides, such as pyrimidine-2-sulfonyl chloride and benzimidazole-2-sulfonyl chloride are unstable at room temperature. ${ }^{1-3}$ Pyrimidine-2-sulfonyl chloride rapidly decomposes to 2-chloropyrimidine ${ }^{2}$ and, in the case of benzimidazole-2-sulfonyl chloride, byproducts are 2-chlorobenzimidazole and 2-hydroxybenzimidazole. ${ }^{3}$ Therefore, for entries 10 and 11 in Table 2 and entries 9 and 10 in Table 3, the yields quoted pertain to these byproducts and not to the corresponding sulfonyl chlorides.

\section{References:}

(1) Richard, O.; Roblin, O.; James, W. J. Am. Chem. Soc. 1950, 72, 4890.

(2) Bornholdt, J.; Fjære, K. W.; Felding , J.; Kristensen, J. L. Tetrahedron 2009, 65, 9280.

(3) S. Wright, W.; Hallstrom, K. N. J. Org. Chem. 2006, 71, 1080. 